\title{
Mata Atlântica: Da formação original à fragmentação e o atual estado de conservação em Santa Catarina.
}

\author{
Carla Jane Weber ${ }^{1}$, Felipe de Castro Horta Hoffmann Martins ${ }^{1}$, Gilberto Neppel ${ }^{1}$, Moisés \\ Eduardo Garcia Junqueira ${ }^{1}$, Rosilene Pires de Oliveira ${ }^{1}$ and Fernanda Witt Cidade ${ }^{1}$
}

\begin{abstract}
Resumo
O Brasil é o país com a maior diversidade de espécies de plantas e animais do planeta. A Mata Atlântica figura como terceiro maior bioma e como segunda maior floresta tropical do continente americano. Estudos apontam que restam apenas $12,4 \%$ de floresta preservada. A redução das áreas de vegetação nativa desse bioma, em decorrência da exploração humana, tem elevado as taxas de detrimento de biodiversidade e a diminuição dos recursos genéticos, tornando a Mata Atlântica o segundo bioma mais ameaçado do planeta. A floresta foi reconhecida como Patrimônio Nacional pela Constituição Federal brasileira e teve sua proteção legal aprovada, em 2006 com a lei da Mata Atlântica. Dentre as atividades que mais exercem pressão sobre o bioma destaca-se a expansão urbana, sendo que Santa Catarina é o quarto Estado que mais desmatou este bioma entre 2019 e 2020 . Atualmente o Estado apresenta apenas $46 \%$ sua área original e precisa ser restaurada, para proteger as suas espécies e os serviços ambientais, estas ações precisam ser executadas por todos os setores da sociedade civil.
\end{abstract}

\section{Palavras-chave}

Mata Atlântica, Floresta Ombrófila Densa, Hotspot, Desmatamento

\section{Introdução}

O Brasil é considerado o país com a maior diversidade de espécies de plantas e animais do planeta. Estimativas demonstram que este território deve abrigar em torno de $13 \%$ de todas as espécies do mundo, o que corresponderia a um total de 1,8 milhões de espécies (Lewinsohn \& Prado, 2005). Nesse cenário, a Mata Atlântica figura como terceiro maior bioma e como segunda maior floresta tropical do continente americano, estendendo-se ao longo de 17 estados* brasileiros. Sua abrangência extrapola os limites do território brasileiro, e conta com área total de $1.309 .736 \mathrm{~km}^{2}$ perpassando ainda 3.429 municípios onde residem mais de 145 milhões de pessoas. Estudos apontam que restam apenas $12,4 \%$ de floresta preservada (Fundação SOS Mata Atlântica, 2021).

São integrantes do Bioma Mata Atlântica as seguintes formações florestais: Floresta Ombrófila Densa; Floresta Ombrófila Mista, também denominada de Mata de Araucárias; Floresta Ombrófila Aberta; Floresta Estacional Semidecidual e; Floresta Estacional Decidual, bem como os manguezais, as vegetações de restingas, os campos de altitude, os brejos interioranos e os encraves florestais do Nordeste (Brasil \& Ambiente, 2006).

A Mata Atlântica deve sua existência à espécies e formações ecológicas, aos tipos climáticos que variam de quentes e úmidos a moderadamente frios (mesotérmicos), assim como à diversidade do relevo que contribui regionalmente, para as modificações estruturais da mata (Pereira, 2009). É conhecida como uma das regiões com maior riqueza e endemismo de espécies do planeta bem como, uma das mais ameaçadas, se tornando um dos hotspots mundiais de biodiversidade (Mittermeier et al., 2004; ) (Myers, Mittermeier, Mittermeier, Fonseca, \& Kent, 2000), ou seja, é uma das áreas prioritárias para conservação. Quando comparada com a Floresta Amazônica, a Mata Atlântica apresenta proporcionalmente uma maior diversidade biológica (BRASIL, 2010), reforçando a dimensão de sua importância.

A redução das áreas de vegetação nativa desse bioma tem levado a alarmantes taxas de perdas de biodiversidade e a diminuição dos recursos genéticos (Miers et al 2000), sendo a conservação in situ, a melhor forma de preservar a biodiversidade e a continuidade dos processos evolutivos.

$\mathrm{O}$ estudo a seguir busca de maneira breve e direta, revisar sobre as principais características da Mata Atlântica enquanto bioma e sua espacialização, sempre buscando enfocar seus atributos no estado de Santa Catarina, buscando vislumbrar seu atual estado de conservação, como se deram os processos de perda florestal e os atuais mecanismos de preservação e restauração ambiental.

\footnotetext{
${ }^{1}$ Instituto Federal Catarinense, Araquari, Santa Catarina, Brasil Emails: carlajaneweber@gmail.com (Carla Jane Weber), gilbertoneppel@epagri.sc.gov.b (Gilberto Neppel)

\section{Corresponding author:}

Felipe de Castro Horta Hoffmann Martins, Instituto Federal

Catarinense, Araquari, Santa Catarina, Brasil

Email: felipehoffmann@gmail.com

$\otimes_{1}$ Rio Grande do Sul, Santa Catarina, Paraná, São Paulo, Goiás, Mato Grosso do Sul, Rio de Janeiro, Minas Gerais, Espírito Santo, Bahia, Alagoas, Sergipe, Paraíba, Pernambuco, Rio Grande do Norte, Ceará e Piauí
} 


\section{Metodologia}

A elaboração do material se pautou em uma revisão bibliográfica, tendo para tanto, sido dividido em temas para fins de busca e redação no estudo como legislação, formação natural, o processo de degradação e o status atual do bioma.

Esta revisão foi realizada com auxílio de publicações científicas como artigos científicos de revistas e livros especializados. Além destes materiais, foram consultados também endereços eletrônicos de instituições governamentais e nãogovernamentais com respaldo científico no assunto.

De posse de uma série de materiais resultantes das pesquisas realizadas, foram organizadas reuniões para filtragem, debates e organização dos mesmos, bem como para definições de pautas e abordagens aos assuntos mencionados no produto resultante.

\section{Aspectos legais de interesse}

Mesmo intensamente citada em artigos e produções científicas que argumentam acerca da importância de sua preservação, a Mata Atlântica, cujo reconhecimento como Patrimônio Nacional se deu pela Constituição Federal brasileira de 1988 (art. 225) e teve sua proteção legal aprovada somente 18 anos depois, em 2006 com a validação da lei de proteção da Mata Atlântica.

No sentido da regulamentação acerca do componente florestal brasileiro, o Código Florestal, foi criado como mecanismo de controle, este orienta a forma como a terra pode ser explorada, estabelecendo onde a vegetação nativa tem de ser mantida e onde pode haver diferentes tipos de exploração.

Atualmente é conhecido como o novo Código Florestal, pois foi atualizado através da Lei 12.651 de 25 de maio de 2012 que "determina normas sobre a proteção da vegetação nativa em geral, incluindo Áreas de Preservação Permanente (APP), de Reserva Legal (RL) e de Uso Restrito (UR); a exploração florestal, o fornecimento de matéria-prima florestal, o controle da origem dos produtos florestais, o controle e prevenção dos incêndios florestais, e a previsão de instrumentos econômicos e financeiros para o alcance de seus objetivos"

Os dados têm comprovado que Código Florestal é uma política fundamental, mas insuficiente para promover o alcance das metas de restauração estabelecidas para a Mata Atlântica. Esta deve ser complementada por políticas públicas e instrumentos privados de incentivo à restauração e uma economia florestal.

A aplicabilidade do Código Florestal na Mata Atlântica tem sido objeto de intensas discussões técnico-jurídicas, especialmente perante os órgãos ambientais responsáveis pela fiscalização e licenciamento de imóveis rurais localizados nesse bioma.

O bioma Mata Atlântica, por sua vez, é regulamentado pela Lei $\mathrm{n}^{\mathrm{o}} 11.428 / 2006$ e pelo Decreto Federal $\mathrm{n}^{\mathrm{o}}$ $6.660 / 2008$, que dispõem detalhadamente sobre a utilização e proteção da vegetação nativa. Anteriormente, vigorava um decreto datado de 1993.

Tal regulamentação possibilitou que os órgãos ambientais, especialmente no âmbito federal, tenham vindo a promover, nos últimos anos, diversas operações fiscalizatórias nas propriedades rurais inseridas no bioma mata atlântica, lavrando autos de infração em todas as áreas objeto de supressão vegetal não autorizada após 11 de fevereiro de 1993, impondo a obrigação de recuperação acrescida de sanções pecuniárias elevadas.

O Parecer $n^{\circ}$ 0115/2019/DECOR/CGU/AGU, em ligeira síntese, concluiu que a Lei da Mata Atlântica (Lei $\mathrm{n}^{\circ}$ 11.428/2006) prevê explicitamente a aplicação do Código Florestal ao referido bioma, defendendo o entendimento de que os regramentos especiais disciplinam a ocupação rural e urbana, de forma a harmonizar o crescimento econômico com a manutenção do equilíbrio ecológico.

\section{Mata Atlântica e sua ocorrência em Santa Catarina}

Dentre os 17 estados em áreas de ocorrência da Mata Atlântica, apenas o Espírito Santo, Rio de Janeiro e Santa Catarina encontram-se totalmente inseridos nos limites do bioma, nestes locais ainda são encontrados importantes fragmentos florestais em diferentes estágios de sucessão, restando, entretanto, poucos remanescentes de floresta primária (Vibrans et al., 2012 a 2015).

Anteriormente o bioma cobria grandes áreas contínuas, o que hoje foi reduzido a pequenos fragmentos florestais, em função principalmente, da exploração descontrolada dos recursos naturais e da ocupação desordenada do território. A vegetação remanescente nesse bioma é extremamente fragmentada quando comparada com sua dispersão original (Ribeiro, Metzger, Martensen, Ponzoni, \& Hirota, 2009).

\section{Formação Original}

A Mata Atlântica figura como segundo domínio em ordem de dispersão geográfica do Brasil, sendo reconhecida como um complexo tipo de vegetação cuja feição distribuída espacialmente na região sul, figura como de importante endemismo (Marques, Swaine, \& Liebsch, 2011)

Sua complexidade deriva principalmente das grandes variações geográficas ao longo de sua área de ocorrência associada com variações climáticas, o que causa variações exclusivas em suas fisionomias (Marques et al., 2011).

Um dos grandes biomas brasileiros e uma das florestas mais ricas em biodiversidade do planeta, o bioma originalmente abrangia cerca de $15 \%$ do território e hoje abriga contingente superior a $70 \%$ da população brasileira. Desta forma em função da grande pressão sobre essa mata, atualmente restam $12,4 \%$ de sua vegetação original. (FUNDAÇÃO SOS MATA ATLÂNTICA).

Ainda segundo essa mesma instituição, dentre as atividades que mais exercem pressão sobre o bioma destacase a expansão urbana descontrolada. Três dos maiores centros urbanos sul-americanos se encontram sob seu domínio, que a despeito de todas as demais sabidas relevâncias, fornece água para $60 \%$ da população brasileira. (FUNDAÇÃO SOS MATA ATLÂNTICA)

De acordo com o mapeamento da cobertura vegetal na área de aplicação da Lei da Mata Atlântica, conforme Lei Federal no $11.428 / 2006$ e Decreto no $6.660 / 2008$, e conforma mencionado, o estado catarinense se encontra integralmente inserido em área do domínio da Mata Atlântica, sendo 
observado em seu território as unidades fitogeográficas da Floresta Ombrófila Densa, também denominada por Floresta Tropical Pluvial, nas áreas de menor altitude no território e a Floresta Ombrófila Mista, cuja denominação se dá pela associação entre coníferas e folhosas, em zonas com altitudes superiores a 500 metros (FUNDAÇÃO SOS MATA ATLÂNTICA; INPE, 2018).

A Floresta Ombrófila Densa compreende zona de alta incidência de pluviosidade e grande diversidade de florestas densas relativamente próximas ao mar (Marques et al., 2011). Já a Floresta Ombrófila Mista, onde se observam as Araucárias, coníferas nativas do Brasil, se encontram nas zonas mais altas e frias do estado, sendo a formação florestal mais sensível às variações climáticas e muito seletiva em relação à temperatura e umidade. (Fritzsons, Mantovani, Eduardo, Wrege, \& Catarina, 2017)

\section{Processo de Degradação}

Os ecossistemas florestais brasileiros vêm sofrendo grande pressão ao longo dos tempos, sobretudo e com mais intensidade, no século XIX e XX. Antes deste período supõe-se que a devastação provocada pelos seres humanos tinha pouca expressão se comparado ao visto na atualidade (Carvalho, 2012).

Estudos desenvolvidos com levantamentos e análises históricas de imagens de satélite demonstram que os ambientes florestais perderam cerca de 61 milhões de hectares ou $10 \%$ da massa florestal no período entre 1985 a 2017 (Souza et al., 2020).

Sua rica biodiversidade transformou a Mata Atlântica em um grande alvo de desmatamento e exploração humana, tornando-a o segundo bioma mais ameaçado do planeta, segundo a Associação de Preservação do Meio Ambiente e da Vida (APREMAVI,2021).

Conforme informações do Atlas da Mata Atlântica entre 2019 e 2020, o desmatamento da Mata Atlântica se intensificou em dez dos dezessete estados abrangidos pelo bioma: Rio Grande do Sul, Santa Catarina, Ceará, Alagoas, Rio Grande do Norte, Goiás, Rio de Janeiro, Mato Grosso do Sul, São Paulo e Espírito Santo. No total, foram desflorestados 13.053 hectares (130 quilômetros quadrados) da Mata Atlântica neste período. (FUNDAÇÃO SOS MATA ATLÂNTICA; INPE, 2021).

Santa Catarina é o quarto Estado que mais desmatou a Mata Atlântica entre 2019 e 2020, atingindo cerca de $25 \%$ a mais em relação ao ano anterior, perfazendo um total de 887 hectares, segundo levantamento da Fundação SOS Mata Atlântica e do Inpe. (FUNDAÇÃO SOS MATA ATLÂNTICA; INPE, 2021). Estes dados são extraídos através de levantamento por meio de imagens de satélite orbitais do sensor OLI/Landsat 8 e por geoprocessamento.

Em alguns casos o desmatamento foi promovido por fatores naturais, porém na sua maioria é por ação antrópica. Nota-se que no processo de degradação do bioma as causas são muitas, como: aumento da urbanização, queimadas, expansão agropecuária, exploração de recursos naturais, onde geralmente incluem a necessidade de se explorar as florestas para fins econômicos.

A problemática do desmatamento tem reflexos em toda a tríade da sustentabilidade, afetando os pilares ambientais, sociais e econômicos, algumas podendo ser irreversíveis. Segundo Henrique Nascimento (2018) as quatro principais consequências do desmatamento são: alteração do clima, erosão no solo, degradação de habitat e perda da biodiversidade.

\section{Ações de recuperação e sustentabilidade na Mata Atlântica}

A Mata Atlântica perdeu cerca de 90\% de sua área original e agora precisa ser restaurada, para proteger as suas espécies e os serviços ambientais. As iniciativas de restauração florestal de um ecossistema devem possuir como objetivo o reestabelecimento não somente da estrutura vegetal, mas também da ecologia destas comunidades, de uma forma que facilite a recuperação natural desses ecossistemas ( ; Gomez et al., 2004) (Engel \& Parrota, 2003).

A maior parte dos estudos sobre restauração florestal da mata atlântica se concentra no sudeste e sul do Brasil, sendo que, a escolha do melhor método de restauração está relacionada a aspectos locais da área a ser restaurada, como características de paisagem, resiliência, processo de degradação e a fatores econômicos (Oliveira, 2017).

Ações restauradoras devem estar ligadas desde a remoção de fatores de perturbação e isolamento da área para que a regeneração natural ocorra de forma passiva (Aide et al., 2000; Wadt, 2003) ou através da interferência do homem através de técnicas para acelerar e influenciar a trajetória da sucessão natural do local ou seja a restauração ativa (Aide et al., 2000; Wadt, 2003)

$\mathrm{Na}$ restauração da mata atlântica a técnica mais comumente utilizada tem sido o plantio direto de árvores (Lamb, 2005; Rodrigues, 2011; Oliveira, 2017), mas recentemente outras técnicas vêm sendo incorporadas, como a semeadura direta e as técnicas nuleadoreas (instalação de poleiros, transposição de galharia e serrapilheira, chuva de sementes e transposição de plântulas) (Reis,2009), além dos sistemas agroflorestais, em menor escala, assim como a condução da regeneração natural.

A condução da regeneração natural tem se mostrado promissora, e com baixo custo em ambientes em que existe relativa resiliência, e é uma técnica aceita pela legislação vigente (BRASIL, 2012).

A floresta nativa que foi dirimida pelo homem ao passar dos anos, precisa agora ser recuperada, para proteger a vida no nosso planeta, a fragmentação dos habitats é a maior causa do desaparecimento de biomas e deve ser amplamente combatido, sendo a restauração florestal um importante mecanismo para conservação e ampliação da Mata Atlântica.

\section{Status Atual}

O retrato mais atualizado sobre o bioma é obtido por uma iniciativa de rede colaborativa entre ONG's, universidades e empresas de tecnologia, que contam com vários especialistas nos biomas, no uso das terras, no sensoriamento remoto, ciência da computação, inteligência artificial, processamento em nuvem e em classificadores automatizados, desenvolvidos e operados a partir da plataforma Google Earth Engine, gerando uma série histórica de mapas. Essa iniciativa pertence ao MapBiomas Brasil (mapbiomas.org). 
De acordo com a Fundação SOS Mata Atlântica, atualmente, restam apenas $12,4 \%$ da floresta e desses remanescentes, cerca de $80 \%$ estão localizados em áreas privadas. Os $12,4 \%$ de floresta original correspondem a todos os fragmentos de floresta nativa acima de três hectares.

De acordo com a WWF e seu acompanhamento baseado em informações dos últimos 36 anos, ou seja, de 1985 a 2020 e em contraste, num cenário geral, o que se tem é que hoje a Mata Atlântica corresponde a 7\% da cobertura original, segundo o WWF (WWF BRASIL (2021)).

Independente de certa discrepância de números, o fato é que o bioma requer atenção especial para ações de acompanhamento, preservação e de recuperação.

Atualmente, os remanescentes florestais são muito fragmentados, onde temos que: $29 \%$ do bioma é coberto por Formações Florestais (Mata, Savana, Mangue e Restinga Florestados); 31\% do bioma é coberto por Vegetação Nativa (incluindo Savana, Campos e Várzeas) e 69\% do bioma tem uso antrópico.

Nesse recorte atualizado, há que se considerar que há aumento significativo das áreas de florestas plantadas, com aumento de $77,9 \%$, muito em substituição as nativas, que variou negativamente em 4,3\%; aumento de $43 \%$ da área de agricultura, que nos últimos anos se deve ao aumento de preços das commodities agrícolas, em substituição às áreas de pastagens que variou em 40,5\% negativamente. É significativo ainda o aumento de outros usos em 8,8\%, que se devem principalmente às áreas de urbanização e ainda aumento de áreas mistas de mosaicos de agricultura e pastagem, da ordem de $4,4 \%$.

Esse mesmo recorte temporal (1985 a 2020) e de ocupação do solo para o estado de SC, evidencia uma estabilidade de áreas de agricultura, com pequenas variações ao longo dos anos, com o mesmo perfil de variação para os mosaicos de agricultura e pastagens, bem como as áreas de pastagens somente. Mas com evidente crescimento de florestas plantadas, reflexo de aumento da demanda mundial por derivados da celulose e vocação regional para essa produção.

Nessa fotografia, percebe-se evidente aumento de áreas antropizadas, em detrimento principalmente das áreas florestais nativas, tanto nacionalmente, como para o âmbito estadual.

Por outro lado, Santa Catarina é destaque entre os estados, ocupando o quarto lugar com maior cobertura nativa, em $46 \%$ do território, juntamente com o Piauí (89\%), Ceará $(67 \%)$ e Bahia (48\%).

Significa que, se a Mata Atlântica está entre 7 a $20 \%$ da cobertura original, em Santa Catarina a degradação foi menor, o que não anula o fato de ter significativas áreas antropizadas. O que preocupa é que há uma constante e contínua antropização da cobertura original nas últimas décadas no Estado, apontada no relatório do Projeto MapBiomas Brasil.

Ainda sobre Santa Catarina, há uma evidente percepção que nas faixas litorânea e serrana predominam os remanescentes florestais. Já na faixa oeste predominam as áreas de agricultura, os mosaicos mistos de agricultura e pastagens e pontos de predominância de pastagens. Ou seja, pode-se depreender que o lado oeste antropizou mais que o restante do estado, ainda que se saiba que nas demais regiões há sim a presença marcante das atividades agrícolas, demandando atenção para focos isolados de supressão de áreas de florestas, nativas ou em estágios diversos de regeneração.

Um outro dado apontado é que a supressão tem se mantido nesse período de monitoramento, pois $31,2 \%$ da floresta nativa foi suprimida nesses 36 anos, dos quais, $27,8 \%$ sofreram algum tipo de regeneração, mas considerada sem qualidade, ou seja, há substituição por atividades econômicas. Em outras palavras, de 10 milhões de hectares suprimidos, 9 milhões são exploradas pelo extrativismo e posteriormente abandonadas ou subocupadas, mas o restante é para substituição propriamente dita, por pastagens, agricultura, urbanização ou outras atividades, o que representa número expressivo e que deve ser combatido, pois são 30 mil hectares anuais. Há ainda uma boa parcela dessa área abandonada ou subocupada que vai passar ao estágio de não persistência, pois em um dado momento futuro terá alguma forma de ocupação e uso, que não a regeneração.

A conservação dos escassos remanescentes depende do engajamento de diferentes setores da sociedade, além de políticas públicas eficazes (Cunha; Guedes, 2013; Rezende et al., 2018).

Atualmente Santa Catarina possui, segundo o IMA 187 Unidades de conservação, em nível municipal, estadual, federal ou particular, sendo 114 não demarcadas e 73 já demarcadas, essas áreas são fundamentais para conservação do que sobrou do bioma.

\section{Considerações Finais}

É fácil notar a dimensão da perda de espaço natural e cobertura vegetal no Brasil, tendo sido esse processo intensificado nos finais do século XX e nos anos do século atual, embora seja nesse período que sua proteção legal também começou a ser pensada, demandada e regulamentada.

A floresta atlântica está posicionada no território brasileiro, mas não se restringe a ele e originalmente está dispersa de maneira que a coloca vulnerável desde o período das invasões portuguesas sobre os territórios dos nativos brasileiros. Seus limites concentram a maior parte da população brasileira há centenas de anos e atualmente comporta mais 150 milhões de indivíduos.

São inúmeras as pressões a que esse bioma foi e é submetido sendo as principais, a intensificação do processo de urbanização e a expansão das áreas agrícolas no país. A primeira salientada nas regiões sudeste e sul e a segunda, nas posições mais a oeste no limite do bioma em importantes zonas de ecótonos nas transições com o bioma Cerrado.

Atualmente o bioma conta com aproximadamente um décimo de seu limite original restando fragmentos reduzidos e isolados de biomas e ecossistemas associados. A fragmentação que leva ao grande detrimento da biodiversidade, apresentando, também, importantes reflexos sociais e econômicos, que se manifestam dentre outras maneiras, nos eventos cada vez mais recorrentes de escassez hídrica.

Nesse ínterim, Santa Catarina aparece como um dos estados com maior percentual de área preservada seja com 
feições de Floresta Ombrófila Densa ou Floresta Ombrófila Mista, mesmo assim ficou evidente a intensificação da perda de floresta nativa em patamares preocupantes apresentadas nos relatórios recentes do Projeto MapBiomas Brasil. O recorte apontado para este território destaca que a parcela oeste catarinense deve priorizar ações de regeneração ambiental, enquanto a porção leste deve priorizar a preservação, mas ambos devem ter atenção para frear a degradação de novas glebas.

Os riscos e perdas decorrentes da degradação do bioma são imensuráveis. Existem mecanismos legais de proteção, mas estes são insuficientes sem uma massiva atuação no sentido não somente da proteção, mas além e sobretudo da recuperação de áreas. As ações precisam ser abraçadas por todos os setores da sociedade civil, incluindo empresas e organizações não governamentais, e sendo coordenada e liderada pelos poderes públicos das três esferas, partindo da esfera Federal.

\section{Referências Bibliográficas}

\section{References}

Ambiente, M. M. D. M. (2006).

Atlântica, F. S. M. (2020). Retrieved from https://www. sosma.org.br/. Acessoem: 21dejulhode2021

Brasil, \& Ambiente, M. D. M. (2006). Dispõe sobre a utilização e proteção da vegetação nativa do Bioma Mata Atlântica, e dá outras providências. Presidência da República, Casa Civil. In Subchefi a para Assuntos Jurídicos.

Brasil, W. (n.d.). Retrieved from https:// www.wwf.org.br/natureza brasileira/ areas_prioritarias/mata_atlantica/

De, M. X., \& Carvalho, M. (2012). (Vol. 18). Retrieved from https://doi.org/10.5007/ 2175-7976.2011v18n25p32

De, R. E., Oliveira, V., \& Lex, E. (2017).

Engel, V. L., \& Parrota, J. A. (2003). Definindo a restauração ecológica: Tendências e perspectivas mundiais (KAGEYAMA \& P. Y. et al., Eds.). Botucatu: FEPAF.

Fritzsons, E. ., Mantovani, L., Eduardo, ., Wrege, M. S., \& Catarina, B. (2017).

Gómez-Aparicio, L. (2004). Applying plant facilitation to forest restoration: a meta-analysis of the use of shrubs as nurse plants. Ecological Applications, 1128-1138.

(n.d.). Retrieved from https://mapbiomas.org/

vegetacao-nativa-perde-espaco-para

-a-agropecuaria-nas-ultimas-tres

- decadas

Inpe, F. S. M. A. (2018). Retrieved from

https://www. sosma.org.br/projeto/

atlas-da-mata-atlantica/dados-mais -recentes/

Lewinsohn, T. ., \& Prado, P. (2005).

Marques, M. C. M., Swaine, M. D., \& Liebsch, D. (2011). Diversity distribution and floristic differentiation of the coastal lowland vegetation: Implications for the conservation of the Brazilian Atlantic Forest. Biodiversity and Conservation, 20(1), 153-168.
Myers, N., Mittermeier, R. A., Mittermeier, C. G., Fonseca, G. A. D., \& Kent, J. (2000). Biodiversity hotspots for conservation priorities. Nature.

Pereira, A. B. (2009). Mata Atlântica: uma abordagem geográfica. Nucleus. Abr.

Ribeiro, M. C., Metzger, J. P., Martensen, A. C., Ponzoni, F. J., \& Hirota, M. M. (2009). The Brazilian Atlantic Forest: How much is left, and how is the remaining forest distributed? Implications for conservation. Biologicalconservation.

Souza, C. M. ., Shimbo, J. Z. ., Rosa, M. R. ., Parente, L. L. ., Alencar, A. A. ., Rudorff, . . . Azevedo, T. (2020). Reconstructing three decades of land use and land cover changes in brazilian biomes with landsat archive and earth engine. Remote Sensing, 12(17).

Teixeira, Lucimara, ., Azevedo, F., Dall, ., Ara, ., Dalmas, F., ... De (2018). Fragmentação Da Paisagem No Município De Bragança Paulista-Sp. Ciência Florestal, 28(3), 937-937. 